\title{
Current trends in needle-free jet injection: an update
}

This article was published in the following Dove Press journal:

Clinical, Cosmetic and Investigational Dermatology

\author{
Daniel Barolet ${ }^{1,2}$ \\ Antranik Benohanian ${ }^{3}$ \\ 'RoseLab Skin Optics Research \\ Laboratory, Laval, QC, Canada; \\ ${ }^{2}$ MUHC Dermatology Service, \\ Department of Medicine, McGill \\ University, Montreal, QC, Canada; \\ ${ }^{3} \mathrm{CHUM}$ Service de Dermatologie, \\ Université de Montréal, Montréal, QC, \\ Canada
}

Background: Jet injection can be defined as a needle-free drug delivery method in which a high-speed stream of fluid impacts the skin and delivers a drug. Despite 75 years of existence, it never reached its full potential as a strategic tool to deliver medications through the skin.

Objective: The aim of this review was to evaluate and summarize the evolution of jet injection intradermal drug delivery method including technological advancements and new indications for use.

Methods: A review of the literature was performed with no limits placed on publication date. Results: Needleless injectors not only reduce pain during drug delivery but also confine the drug more evenly in the dermis. Understanding skin properties of the injection site is a key factor to obtain optimal results as well as setting the right parameters of the jet injector. Until the advent of disposable jet injectors/cartridges, autoclaving of the injector remains the only reliable method to eliminate the risk of infection. Needle-free intradermal injection using corticosteroids and/or local anesthetics is well documented with promising indications being developed.

Limitations: Limitations of the review include low-quality evidence, small sample sizes, varying treatment parameters, and publication bias.

Conclusion: New developments may help reconsider the use of jet injection technology. Future studies should focus on measurable optimized parameters to insure a safe and effective outcome.

Keywords: needle free, injector, jet injection, xylocaine, triamcinolone, PDT

\section{Introduction}

Jet injectors have been used for 75 years to rapidly vaccinate millions of people in need of immunization. The results proved convincing as, by 1990, no more smallpox epidemics were reported by the Center for Disease Control. ${ }^{1,2}$ Despite this accomplishment, jet injection never reached its full potential as a strategic tool to deliver medications through the skin. ${ }^{3}$ Its general acceptance in routine dermatological practice remained low due to many concerns, such as risk of infection, ${ }^{4}$ pain during injection, ${ }^{5}$ bruising, ${ }^{6}$ perforation, ${ }^{7}$ neuropathies,${ }^{8}$ accidental injury of the operator's finger, ${ }^{9}$ subungual hemorrhage, cellulitis, ${ }^{10}$ and a single unpublished report of amputation of a digit due to an epidermal inclusion cyst that followed Dermojet ${ }^{\circledR}$ (Dermojet, Friedrichshafen, Germany) injection. ${ }^{11}$ Technical difficulties such as clogging of the injector, splash, and splatter were among other factors that discouraged practitioners to use jet injection technology and favor the traditional syringe-needle method.

The newly designed jet injectors have overcome most of these difficulties by introducing adjustable parameters selected according to the skin-site properties and thickness $^{12}$ as well as the desired depth level intended to deliver the medication. In
Correspondence: Daniel Barolet RoseLab Skin Optics Research Laboratory, 3333, I00th Avenue, Laval, QC H7T 0G3, Canada

Tel +l 4506864744

$\mathrm{Fax}+\mathrm{I} 4506869558$

Email daniel.barolet@mcgill.ca 
this review, we focus on the dermatological use of jet injectors beyond vaccines and systemic drug delivery methods, namely needle-free intradermal injection (NFII) of specific drugs/medications.

\section{Definition}

NFII can be defined as a needle-free drug delivery method in which a high-speed stream of fluid impacts the skin and delivers a drug ${ }^{13}$ excluding vaccines and systemically absorbed medications like insulin. The fluid can contain a corticosteroid, ${ }^{14}$ an anesthetic agent, ${ }^{14}$ onabotulinum toxin A (BoNT-ONA), ${ }^{15,16}$ bleomycin, ${ }^{17}$ 5-aminolevulinic acid (ALA), ${ }^{18}$ or any injectable substance.

Two types of NFII injectors exist: ${ }^{19}$

- Spring-loaded jet injector

- Gas-powered jet injector

Spring-loaded jet injector works on a spring mechanism which is drawn back. The spring is released by hitting trigger leading to the generation of jet stream of drug for the delivery of a drug. The activated spring load must be redrawn manually for the next administration. Gas-powered jet injector consists of an air/gas cartridge that is attached to the gun through a tubing system that delivers power to the piston after trigger actuation; it releases the piston and creates jet stream of drug. Both are suitable for subcutaneous, intramuscular, or intradermal use; the latter is discussed in the following sections.

\section{Risks and challenges Infections}

Although no hepatitis was reported following the largescale use of jet injection in the 1940s, an outbreak of hepatitis B happened in $1990,{ }^{4}$ revealing a definite risk of infection if appropriate measures of sterilization are not taken for each patient. Dimache et $\mathrm{al}^{20}$ conceived an anticontaminant disposable device that was interposed between the patient's skin and the jet injector. A study carried out with such device among 22,714 participants showed no risk of contamination. Weintraub and Ponce de Leon ${ }^{21}$ also used a similar disposable device and came to the same conclusion. However, since it does not eradicate the risk completely, the use of a sterile jet injector for each patient is imperative. ${ }^{22}$ Injection should not be performed on known infected sites to prevent potential spread of infection in the same patient. In addition, any leftover injectable liquid in the reservoir of the injector should be discarded. For this reason, future developments should focus on disposable cartridges for single-dose devices. ${ }^{23}$

\section{Pain management}

Jet injection of $1 \%$ lidocaine provides immediate analgesia of the skin including the palms and soles. Jet injection is particularly helpful for patients who need multiple needle injections and/or needle-phobic patients. ${ }^{24}$ Taddio et $\mathrm{al}^{25}$ reported that $24 \%$ of the adult population and $63 \%$ of children in the USA fear needles.

A pain score of 3 is considered to be the boundary between mild and moderate pain ${ }^{26}$ which means that a score of $\leq 3$ is an acceptable amount of pain. Zsigmond ${ }^{27}$ observed that zero pain scores were consistently observed in more than 100,000 persons who received jet injection of lidocaine (jet anesthesia), while other investigators have stated that jet injection is more painful than traditional needle injection. ${ }^{5}$ Goodenough et $\mathrm{al}^{28}$ reported that observed facial expression is more reliable in measuring pain intensity than self-reporting techniques. Apart from the mechanical properties of the skin site to be injected, pain sensitivity is affected by age, anxiety level, cultural background, and genetic traits as well as a wide range of interpersonal variability. The average thickness of the epidermis is about $0.1 \mathrm{~mm}$, but it can vary from $0.04 \mathrm{~mm}$ on the eyelid to $1.6 \mathrm{~mm}$ on the palm. Jet injection into certain anatomical areas, such as the periocular area, should be performed with great caution to avoid eye injury. ${ }^{29}$ Of all the skin covering the body, none is thicker and as densely innervated as the skin covering the palms and soles. Lamarche et $\mathrm{al}^{30}$ reported that EMLA application is effective in easing the pain of electromyography needling in forearm skin, but it is ineffective when applied to the skin of the palmar surface of the hand. This may explain why needle injection on the palms and soles, contrary to other sites on the body such as the axillae, requires an adequate pain management method. ${ }^{31}$

BoNT-ONA has been successfully used to treat patients with severe palmar hyperhidrosis $(\mathrm{HH})$, but pain during needle puncture has always been a major problem. Jet anesthesia prior to BoNT-ONA injection with needle ranked among the preferred pain management methods among our patients who previously tried the following: nerve block, cryoanalgesia, and the vibration methods. NFII parameters play a major role in pain perception and that is why good results have been reported with some devices and disappointing ones with others. ${ }^{32}$ Unfortunately, since 
these parameters are not always revealed in the literature, it is hard to objectively compare results. Jet injection parameters include the following: driving pressure, contact pressure, volume per spurt, aperture of the nozzle, and the distance from the tip of the nozzle to skin surface.

\section{Emerging NFII parameters}

Delivery of the injectate into the superficial layer of the dermis needs a low-pressure setting. In this section, we will examine the following parameters to further optimize NFII delivery of the injectate into the superficial layer of the dermis; a lowpressure setting, a firm contact pressure, a small volume per spurt, a small orifice (opening of the nozzle), and an optimal distance $(1 \mathrm{~mm})$ from the tip of the nozzle to the skin surface (spacer). Deeper penetration levels increase pain perception and the risk of injury to vital vascular and nerve structures.

\section{Driving pressure}

Traditional jet injectors such as the Dermojet and the Madajet ${ }^{\mathbb{R}}$ (Mada Medical Products, Inc., Carlstadt, NJ, USA) are spring loaded and therefore have a fixed driving pressure. The driving pressure of the Dermojet is $1,420 \mathrm{psi}$ (pounds per square inch), whereas that of the Madajet is 1,800 psi. These devices do not work universally on different areas of the body, and some manufacturers even warn against their use on the hands and fingers. Naumann et al have used the Dermojet safely to inject BoNT-ONA directly into the skin for plantar $\mathrm{HH}$, but they did not advocate its use for palmar $\mathrm{HH}$ from the fear of damaging vital superficial nerves and vessels. ${ }^{9}$ Cohen and Lerner ${ }^{7}$ observed perforation of the buccal mucosa during the injection of triamcinolone acetonide with Dermojet while treating a case of atrophic lupus erythematosus on the cheek. However, high-pressure jet injectors are particularly useful and safe to treat certain skin conditions such as keloids and hypertrophic scars. ${ }^{33}$ Mitragotri ${ }^{3}$ reported that traditional jet injectors may cause pain due to the jet's deeper penetration level. Wolf et $\mathrm{al}^{34}$ reported that a driving pressure above 435 psi could cause considerable harm to the skin and underlying structures. The authors have also observed increased pain with higher driving pressure settings. Low-pressure settings (130-160 psi) are safer and associated with lower pain scores approaching zero while maintaining a reasonable depth of penetration. ${ }^{35}$ A detailed comparison of traditional high driving pressure versus new low driving pressure jet injectors is summarized in Table 1.

\section{Contact pressure}

A firm and steady contact pressure between the tip of the injector and the skin surface must be maintained by the operator as a loose contact might not deliver the injectate at the desired depth.

\section{Volume per spurt}

Larger volumes per spurt increase the depth penetration level $^{36}$ and also increase pain perception. ${ }^{37}$ Gaylarde et al demonstrated that the volume of liquid entering the skin is less than the volume the injector is set to deliver. The discrepancy between the volume set on the injector and the actual volume that penetrates the skin is due to the liquid lost in the splash back during jet injection. The lost volume depends on the distance that separates the nozzle of the injector from the skin surface that is determined by the spacer $(1,2$, or $3 \mathrm{~mm})$. When the tip of the nozzle directly touches the skin surface, the loss is greatly reduced. Of note, when BoNT-ONA is injected with a needle under the arms to control axillary $\mathrm{HH}$, a waste by reflux occurs, which is estimated to be about $15 \%{ }^{39}$

\section{Orifice diameter (internal aperture of the nozzle)}

Gaylarde et $\mathrm{al}^{39}$ were also the first to observe that a wider nozzle diameter $(0.1-0.2 \mathrm{~mm})$ increases the depth penetration level. Contrary to what might be expected, an orifice

Table I Needle-free injectors

\begin{tabular}{|c|c|c|}
\hline Device specifications & Traditional jet injectors & Versatile jet injectors \\
\hline Power source & Spring-loaded: fixed pressure & $\mathrm{CO}_{2}$ powered: versatile pressure \\
\hline Driving power & Fixed may vary from 1,400 to 1,800 psi & $130-300 \mathrm{psi}$ \\
\hline Potential for cross- & Potential for cross-contamination reported with & Disposable nozzle, splash guard with or \\
\hline contamination & older versions of traditional jet injectors & without spacer \\
\hline Volume per spurt & Fixed: $0.1 \mathrm{~mL}$ & Adjustable: $0.03-0.3 \mathrm{~mL}$ \\
\hline Reservoir & $4 \mathrm{~mL}$ & $\begin{array}{l}3,5,10,12 \mathrm{~mL} \text {, or more according to } \\
\text { the syringe size mounted on the device }\end{array}$ \\
\hline Sterilization with autoclave & Autoclave $134^{\circ} \mathrm{C}$ for 18 minutes & \\
\hline
\end{tabular}


of a smaller diameter results in a shallow penetration of the injectate. A wider diameter is always more painful as evidenced with larger bore needles vs smaller bore needles. Evidence now exists that when 32 vs $30 \mathrm{G}$ needles are used for facial injections of the forehead and glabellar complex with BoNT-ONA, the proportion of patients experiencing clinically important pain is reduced significantly..$^{40}$ A $32 \mathrm{G}$ needle has an external diameter of about $25 \%$ smaller than a $30 \mathrm{G}$ needle.

\section{Spacer}

The role of the spacer (a disposable piece that keeps the tip of the nozzle 1-3 $\mathrm{mm}$ from skin surface) is to deliver the injectate at the desired depth penetration level. A spacer of $3 \mathrm{~mm}$ will restrict the injectate to the superficial layer of the dermis, whereas a spacer of $1 \mathrm{~mm}$ may push the injectate into deeper areas in the skin and reduce the amount of liquid lost through splash back. Furthermore, the spacer helps to reduce pain sensitivity during injection and reduces the risk of cross-contamination. ${ }^{41}$

The selection of optimal parameters is crucial for safe and effective injection. ${ }^{42}$ If properly applied, NFII can reduce procedural pain considerably as compared to needles and provide broader diffusion of the injectate intradermally (inverted bulb-shaped distribution). ${ }^{36}$ Recent versatile jet injectors allow for adjustable parameters compared to traditional jet injectors. For instance, one can adjust the volume per spurt and driving pressure which can be 10 times lower than in traditional jet injectors (rapid guide for common procedures is given in Figure 1 and Table 2).

\section{Established and potential clinical applications}

Since the use of NFII for vaccines and systemic drug delivery is beyond the scope of this review, only common dermatological intradermal indications are discussed.

\section{Local anesthesia}

NFII anesthesia with xylocaine is a convenient method of pain management prior to minor surgery such as skin biopsy, removal of superficial tumors, benign or malignant, hair transplant, removal of multiple skin tags, genital warts, and mollusca contagiosa.

It is important to increase the driving pressure gradually until a tiny blood spot or subepidermal wheal appears. Mitragorti believes that restricting jet penetration to superficial layers of skin may significantly minimize pain intensity and potential damage to underlying vessel and nerve structures. ${ }^{3}$ Jet anesthesia has been used by the authors, prior to BoNT-ONA injection with a needle, in more than 700 patients in the past decade (practical guide for the use of NFII to treat palmar $\mathrm{HH}$ is summarized in Table 3). Details of the technique have been published elsewhere. ${ }^{13,43-45}$

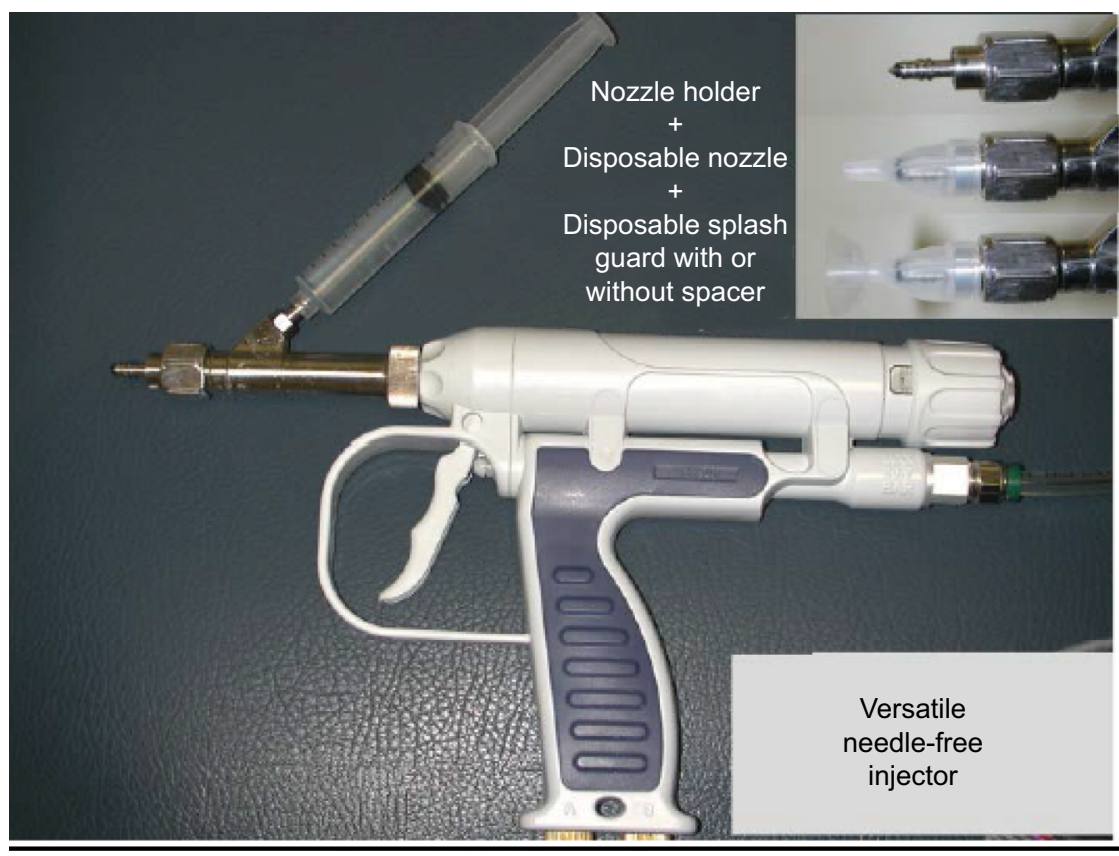

Figure I Versatile needle-free injector.

Note: Newer injectors offer adjustable driving pressure $(130-160 \mathrm{psi})$ and volume per spurt $(0.03-0.3 \mathrm{~mL})$ in addition to disposable nozzles and splash guards with or without a spacer. 
Table 2 A rapid guide for the use of versatile jet injectors for common procedures

\begin{tabular}{|c|c|c|c|c|}
\hline Settings & $\begin{array}{l}\text { Volume per spurt } \\
(\mathrm{mL})\end{array}$ & Pressure (psi) & $\begin{array}{l}\text { Diameter of disposable } \\
\text { nozzle }\end{array}$ & $\begin{array}{l}\text { Use of spacer combined with } \\
\text { splash guard or splash guard } \\
\text { alone }\end{array}$ \\
\hline $\begin{array}{l}\text { Range } \\
\text { Jet anesthesia for } \\
\text { minor surgery or } \\
\text { jet injection of } \\
\text { triamcinolone in } \\
\text { normal epidermis } \\
\text { Jet anesthesia } \\
\text { prior to BoNT- } \\
\text { ONA injection } \\
\text { with needle in } \\
\text { thick epidermis } \\
\text { such as the palms } \\
\text { and soles }\end{array}$ & $\begin{array}{l}\text { A volume of } 0.07- \\
0.1 \mathrm{~mL} \text {; although the } \\
\text { volume seems too small, } \\
\text { yet, it is enough to } \\
\text { provide total anesthesia } \\
\text { when the introduction } \\
\text { of the BoNT-ONA } \\
\text { needle takes place in the } \\
\text { anesthetic wheal }\end{array}$ & $\begin{array}{l}\text { Recommended pressure } \\
\text { I30-|60 psi may be gradually } \\
\text { increased by increments of } \\
10 \text { psi until a wheal (or tiny } \\
\text { blood spot) appears, then } \\
\text { Botox can be injected pain } \\
\text { free. For palms and soles, the } \\
\text { pressure is rarely increased } \\
\text { above } 200 \text { psi, whereas on the } \\
\text { feet, particularly on the heel, a } \\
\text { pressure of up to } 300 \text { psi may } \\
\text { be needed }\end{array}$ & $\begin{array}{l}0.1 \mathrm{~mm} \\
\text { Recommended nozzle } \\
\text { orifice is } 0.1 \mathrm{~mm} \text {; for } \\
\text { skin lesions on the feet } \\
\text { if } 0.1 \mathrm{~mm} \text { is inadequate, } \\
0.15 \text { or } 0.2 \mathrm{~mm} \text { nozzles } \\
\text { could be considered } \\
\text { An orifice of } 0.1 \mathrm{~mm} \text { is } \\
\text { enough to treat the palms. } \\
\text { For the soles, a } 0.2 \mathrm{~mm} \\
\text { orifice may be necessary }\end{array}$ & $\begin{array}{l}\text { If the formation of an anesthetic } \\
\text { wheal or a tiny red blood spot is } \\
\text { still a problem, the spacer could } \\
\text { be removed and a splash guard } \\
\text { could be mounted on the nozzle } \\
\text { so that the nozzle directly touches } \\
\text { the skin. Trimming a few layers } \\
\text { of the stratum corneum with a } \\
\text { scalpel or soaking the area in water } \\
\text { for } 10 \text { minutes is another option } \\
\text { to reach the subepidermis in the } \\
\text { thickest skin of the body }\end{array}$ \\
\hline
\end{tabular}

Notes: The device should be properly prepared before its use; preparation of the versatile jet injector: sterile water or saline is drawn into a standard syringe (usually $10-12 \mathrm{~mL}$ ) which is then mounted on the injector to become its reservoir. The volume per spurt is then set to $0.3 \mathrm{~mL}$ to drive out the air present in the device. Initially, the plunger of the syringe is slowly pushed until we get a straight jet stream. Then, a few shots are fired in the air until a distinctive sound, indicating that the air has been totally expelled, is heard. During the regulation of the volume or pressure, the trigger should always be kept in a semi-pulled position. The syringe is then replaced with the one containing medication to be injected: lidocaine, triamcinolone, BoNT-ONA, etc. ${ }^{a}$ Occasionally, triamcinolone crystals can jam the injector since triamcinolone crystals clog the flow of the injectate. The clogging problem was solved by designing a nozzle holder with a wider diameter $(0.5 \mathrm{~mm})$. This allows the liquid to travel freely until it reaches the tip of the disposable nozzle that has a much narrower diameter $(0.13 \mathrm{~mm})$. Hence, by simply replacing the disposable nozzle, the flow of the injectate is reestablished. Abbreviation: BoNT-ONA, onabotulinum toxin A.

Table 3 Practical guide for the use of NFIl to treat palmar HH prior to BoNT-ONA injection with needles

\section{Useful tips}

I. Jet anesthesia prior to BoNT-ONA injection with needle is a practical pain management technique used by the authors to treat palmar or plantar $\mathrm{HH}$.

2. The volume is set between 0.07 and $0.1 \mathrm{~mL}$ per spurt.

3. The initial driving pressure is set to $140 \mathrm{psi}$, but it could be increased by increments of 10 psi until a wheal or a tiny blood spot appears on the skin surface indicating the site where the needle should be inserted. The average pain score reported with this technique varies from 0 to 2 on a scale of 0 to 10.

\section{Advantages}

I. Tiny amount of lidocaine is used.

II. Immediate analgesia and reduced bleeding: needle injection into the dermis, as compared to the subcutaneous tissue, meets an elevated level of resistance that is felt on the syringe plunger, ${ }^{65}$ and therefore, injection should be performed slowly to minimize pain. This resistance may cause a reflux up to $15 \%$ of the total amount of BONT-ONA injected. Some experts have even suggested the suction of the BONT-ONA droplets on the skin surface caused by backflow and their reinjection. ${ }^{38}$ The authors did not observe any BONT-ONA reflux when jet anesthesia was used as the pain management method.

III. On the other hand, jet injection produces a superficial wheal formed by increased tissue pressure caused by the anesthetic fluid. The increased pressure compresses blood vessels, resulting in reduced bleeding, contrary to the nerve block technique, which induces reactive hyperemia that increases the tendency to bleed and causes waste of the expensive BoNT-ONA.

IV. Broader diffusion: the injected liquid has a bulb-shaped distribution with the broadside facing the muscle fascia and the narrow side underneath the epidermis. ${ }^{36}$ Jet injection distributes lidocaine more extensively into the dermis, thereby allowing BoNT-ONA to reach a greater number of eccrine glands than it would originally do if it would be limited along the needle injection track alone.

V. Avoidance of muscle weakness of the hands by allowing injection of BoNT-ONA as superficial as possible in the dermis where most "free nerve endings" for pain sensation are located. Without anesthesia, subcutaneous injections of BoNT-ONA were found to be relatively less painful than superficial dermal injections, but these deep injections, because of their proximity to the muscles, can cause handgrip weakening. ${ }^{66-68}$

VI. Vagal symptoms occur less frequently with this technique than the nerve block technique and, when they do, they are much milder.

VII. Patients can drive back home safely after the treatment session while patients who had a nerve block at the wrist can hardly do so.

Abbreviations: BoNT-ONA, onabotulinum toxin A; HH, hyperhidrosis; NFII, needle-free intradermal injection. 


\section{Direct palmar BoNT-ONA}

This is particularly suited for patients suffering from disabling palmar $\mathrm{HH}$ who are also needle phobic. ${ }^{46}$ Needle phobia affects at least $10 \%$ of the population: it can be managed by reassurance, education, and avoidance of needles. ${ }^{47}$ It is not uncommon to see patients suffering from disabling palmar $\mathrm{HH}$ who refuse to be treated because of the fear from needle puncture. ${ }^{43}$ While BoNT-ONA injection of the hands with needle following nerve block may take 60-90 minutes to treat one hand, ${ }^{48,49}$ direct jet injection of BoNT-ONA per hand may hardly exceed 1 minute (Table 4). The main disadvantage of this technique is the potential waste of BoNT-ONA due to splash back which could add up to $5 \%-10 \%$ of the total injectate. This can be reduced by using a shorter spacer $(1 \mathrm{~mm})$ or no spacer at all. Until recently, it was believed that the efficacy of BoNT-ONA would decrease through jet injection (shaking and agitation). A recent study refuted that possibility. ${ }^{50}$

\section{Intralesional corticosteroids}

Several skin conditions may require multiple injections of triamcinolone into different sites of the body: extensive alopecia areata, ${ }^{51}$ generalized granuloma annulare, ${ }^{52}$ nail psoriasis, ${ }^{53,54}$ scars, ${ }^{55}$ etc. NFII is a great alternative to needle injections to reduce pain and spread triamcinolone more evenly into intradermal lesions. Typically, $5 \mathrm{~mL}$ of triamcinolone acetonide $(10 \mathrm{mg} / \mathrm{mL})$ is added to $5 \mathrm{~mL}$ of saline in a $10 \mathrm{~mL}$ regular syringe to yield a final concentration of $5 \mathrm{mg} / \mathrm{mL}$. Higher concentrations (ie, $20 \mathrm{mg} / \mathrm{mL}$ ) may also be injected for thick hypertrophic scars and keloids.

\section{Intralesional bleomycin}

Intralesional bleomycin appears to be the most effective treatment for periungual warts. ${ }^{56}$ Agius et al ${ }^{17}$ showed that NFII Dermojet injection of bleomycin may benefit patients with recalcitrant plantar warts. It has also been successfully used to treat keloids and hypertrophic scars that are unresponsive to intralesional corticosteroids..$^{57}$

\section{Intralesional 5-ALA}

In contrast to conventional topical application of ALA in the process of photodynamic therapy (PDT), previous studies report higher fluorescence and protoporphyrin IX levels following intracutaneous needle administration. ${ }^{58,59}$ However, the use of traditional needles may lead to profound vascular compromise with possible vasoconstriction, deep purpura, necrosis, and infection and cause pain. ${ }^{60}$ An alternative technique to enhance the delivery of drugs intradermally is NFII to expand the diffusion of the photosensitizer around the tumor without the side effects of needles. ${ }^{61}$ Using NFII to inject nodular basal cell carcinomas (BCCs) with intralesional 5-ALA 20\% before PDT (photoactivation) led to complete, years-long remissions and few side effects. ${ }^{18}$ This approach represents an interesting alternative to Mohs micrographic surgery that remains the standard of care for BCC in high-risk sites at least in North America. ${ }^{62}$ However, the later can cause noticeable scarring. In contrast, traditional PDT is associated with less scarring and pain, fewer complications, shorter recovery times, and lower costs, although the recurrence rate is about $14 \% .{ }^{63}$ Preliminary data ${ }^{64}$ suggest that intradermal NFII-administered ALA-PDT (NFII-PDT) offers very low risk of recurrence with excellent cosmesis, thus a reasonable alternative to Mohs for BCCs in high-risk body sites (Table 5 ).

\section{Conclusion}

A crucial contribution to the success of NFII involves setting the right parameters using adjustable versatile jet injectors. The focus is now shifting toward user-friendly disposable cartridge jet injectors for single-dose devices eliminating the risk of cross-contamination. ${ }^{23}$ Future study should expand on

Table 5 BCC treatment modalities according to BCC type and anatomical location

\begin{tabular}{lll}
\hline & High-risk BCC & Low-risk BCC \\
\hline High-risk sites & Mohs, NFII & NFIl, Mohs \\
Low-risk sites & Conventional, Mohs, NFII & Conventional \\
\hline
\end{tabular}

Notes: For low-risk sites such as cheeks and forehead, conventional methods (electrodessication and curettage $\times 3$, plain surgery) apply. However, for high-risk sites such as nose, eyebrows and eyelids, lips, ears, or genitalia, one may now consider NFII-PDT especially when cosmesis is important in exposed areas. It can also be used for any BCC in high- or low-risk tumors and sites. NFII-PDT, NFIIadministered ALA-PDT.

Abbreviations: ALA, aminolevulinic acid; BCC, basal cell carcinoma; NFII, needlefree intradermal injection; PDT, photodynamic therapy.

Table 4 Recommended parameters of BoNT-ONA injection through the versatile jet injector

\begin{tabular}{|c|c|c|c|c|c|c|}
\hline $\begin{array}{l}\text { Total number of } \\
\text { BoNT-ONA units }\end{array}$ & $\begin{array}{l}\text { Volume } \\
\text { per spurt }\end{array}$ & $\begin{array}{l}\text { Reconstitution of } \\
\text { BoNT-ONA (mL) }\end{array}$ & $\begin{array}{l}\text { Mouse units } \\
\text { per site }\end{array}$ & $\begin{array}{l}\text { Number of } \\
\text { sites injected }\end{array}$ & $\begin{array}{l}\text { Pressure } \\
\text { (psi) }\end{array}$ & Orifice \\
\hline 100 & 0.1 & 5.00 & 2 & 50 & $\geq 130$ & $0.1 \mathrm{~mm}$ \\
\hline
\end{tabular}

Abbreviation: BoNT-ONA, onabotulinum toxin A. 
tailored parameters pertaining to traditional and new indications of NFII to insure a safe and effective outcome.

\section{Disclosure}

The authors report no conflicts of interest in this work.

\section{References}

1. Hingson RA, Hughes JG. Clinical studies with jet injection; a new method of drug administration. Curr Res Anesth Analg. 1947;26(6):221-230.

2. Zsigmond EK. Jet anesthesia and jet local anesthesia for the 21 st century. J Natl Med Assoc. 2002;94(11):1004-1006.

3. Mitragotri S. Current status and future prospects of needle-free liquid jet injectors. Nat Rev Drug Discov. 2006;5(7):543-548.

4. Canter J, Mackey K, Good LS, et al. An outbreak of hepatitis B associated with jet injections in a weight reduction clinic. Arch Intern Med. 1990;150(9):1923-1927.

5. Arapostathis KN, Dabarakis NN, Coolidge T, Tsirlis A, Kotsanos N. Comparison of acceptance, preference, and efficacy between jet injection INJEX and local infiltration anesthesia in 6 to 11 year old dental patients. Anesth Prog. 2010;57(1):3-12.

6. Murray CA, Cohen JL, Solish N. Treatment of focal hyperhidrosis. J Cutan Med Surg. 2007;11(2):67-77.

7. Cohen IS, Lerner AB. Limitations in the use of the dermo-jet. Arch Dermatol. 1972;105(5):760.

8. Hogan QH. Pathophysiology of peripheral nerve injury during regional anesthesia. Reg Anesth Pain Med. 2008;33(5):435-441.

9. Naumann M, Bergmann I, Hofmann U, Hamm H, Reiners K. Botulinum toxin for focal hyperhidrosis: technical considerations and improvements in application. Br J Dermatol. 1998;139(6):1123-1124.

10. Monoski MA, Li PS, Baum N, Goldstein M. No-scalpel, no-needle vasectomy. Urology. 2006;68(1):9-14.

11. de Berker D. Management of nail psoriasis. Clin Exp Dermatol. 2000;25(5):357-362.

12. Sasaki GH, Travis HM, Tucker B. Fractional CO2 laser resurfacing of photoaged facial and non-facial skin: histologic and clinical results and side effects. J Cosmet Laser Ther. 2009;11(4):190-201.

13. Schramm-Baxter JR, Mitragotri S. Investigations of needle-free jet injections. Conf Proc IEEE Eng Med Biol Soc. 2004;5:3543-3546.

14. Callen JP. Intralesional corticosteroids. J Am Acad Dermatol. 1981;4(2):149-151.

15. Benohanian A. Needle-free anaesthesia prior to botulinum toxin type $A$ injection treatment of palmar and plantar hyperhidrosis. Br J Dermatol. 2007;156(3):593-596.

16. Vadoud-Seyedi J. Treatment of plantar hyperhidrosis with botulinum toxin type A. Int J Dermatol. 2004;43(12):969-971.

17. Agius E, Mooney JM, Bezzina AC, Yu RC. Dermojet delivery of bleomycin for the treatment of recalcitrant plantar warts. J Dermatolog Treat. 2006;17(2):112-116.

18. Barolet D, Boucher A. No-needle jet intradermal aminolevulinic acid photodynamic therapy for recurrent nodular Basal cell carcinoma of the nose: a case report. $J$ Skin Cancer. 2011;2011:790509.

19. Kale TR, Momin M. Needle free injection technology - an overview. Inov Pharm. 2014;5(1):10.

20. Dimache G, Croitoru M, Balteanu M, et al. A clinical, epidemiological and laboratory study on avoiding the risk of transmitting viral hepatitis during vaccinations with the Dermojet protected by an anticontaminant disposable device. Vaccine. 1997;15(9):1010-1013.

21. Weintraub AM, Ponce de Leon MP. Potential for cross-contamination from use of a needleless injector. Am J Infect Control. 1998;26(4):442-445.

22. Rutala WA, Weber DJ; Society for Healthcare Epidemiology of America. Guideline for disinfection and sterilization of prion-contaminated medical instruments. Infect Control Hosp Epidemiol. 2010;31(2):107-117.
23. Moradiafrapoli M, Marston JO. High-speed video investigation of jet dynamics from narrow orifices for needle-free injection. Chem Eng Res Design. 2017;117:110-121.

24. Szmuk P, Szmuk E, Ezri T. Use of needle-free injection systems to alleviate needle phobia and pain at injection. Expert Rev Pharmacoecon Outcomes Res. 2005;5(4):467-477.

25. Taddio A, Ipp M, Thivakaran S, et al. Survey of the prevalence of immunization non-compliance due to needle fears in children and adults. Vaccine. 2012;30(32):4807-4812.

26. Collins SL, Moore RA, McQuay HJ. The visual analogue pain intensity scale: what is moderate pain in millimetres? Pain. 1997;72(1-2):95-97.

27. Zsigmond EK. Findings of study of needle-free jet-injection system with lidocaine are contrary to published reports. Anesth Analg. 2004;98(5):1504. author reply 1504-1505.

28. Goodenough TB, Perrott DA, Champion GD, Thomas W. Painful pricks and prickle pains: is there a relation between children's ratings of venipuncture pain and parental assessments of usual reaction to other pains? Clin J Pain. 2000;16(2):135-143.

29. Perry HT, Cohn BT, JS NA. Accidental intraocular injection with Dermojet syringe. Arch Dermatol. 1977;113(8):1131.

30. Lamarche Y, Lebel M, Martin R. EMLA partially relieves the pain of EMG needling. Can J Anaesth. 1992;39(8):805-808.

31. Benohanian $\mathrm{A}$. What stands in the way of treating palmar hyperhidrosis as effectively as axillary hyperhidrosis with botulinum toxin type A. Dermatol Online J. 2009;15(4):12.

32. Nail Psoriasis EH. Psoriasis. In: Soung DJ, editor. Psoriasis. London: In Tech; 2012:141-186.

33. Zanon E, Jungwirth W, Anderl H. Die cortison-hochdruckinjektion als therapie von hypertrophen narben und keloiden [Cortisone jet injection as therapy of hypertrophic scars and keloids]. Handchir Mikrochir Plast Chir. 1992;24(2):100-102. German.

34. Wolf AR, Stoddart PA, Murphy PJ, Sasada M. Rapid skin anaesthesia using high velocity lignocaine particles: a prospective placebo controlled trial. Arch Dis Child. 2002;86(4):309-312.

35. Seok J, Oh CT, Kwon HJ, et al. Investigating skin penetration depth and shape following needle-free injection at different pressures: a cadaveric study. Lasers Surg Med. 2016;48(6):624-628.

36. Wagner S, Dues G, Sawitzky D, Frey P, Christ B. Assessment of the biological performance of the needle-free injector INJEX using the isolated porcine forelimb. Br J Dermatol. 2004;150(3):455-461.

37. Harding LM, Adeniyi A, Everson R, Barker S, Ralph DJ, Baranowski AP. Comparison of a needle-free high-pressure injection system with needle-tipped injection of intracavernosal alprostadil for erectile dysfunction. Int J Impot Res. 2002;14(6):498-501.

38. Bechara FG, Sand M, Hoffmann K. How to save botulinum toxin A in the treatment of focal axillary hyperhidrosis. Dermatology. 2006;213(4):356.

39. Gaylarde P, Macmillan AL, Sarkany I. Penetration and dose of injections with the Porton jet injector. Br J Dermatol. 1972;86(1):83-86.

40. Alam M, Geisler A, Sadhwani D, et al. Effect of needle size on pain perception in patients treated with botulinum toxin type A injections: a randomized clinical trial. JAMA Dermatol. 2015;151(11):1194-1199.

41. Brink PR, van Loon AM, Trommelen JC, Gribnau FW, Smale-Novakova IR. Virus transmission by subcutaneous jet injection. J Med Microbiol. 1985;20(3):393-397.

42. Nantel-Battista M, Vadeboncoeur S, Benohanian A. Selection of safe parameters for jet injection of botulinum toxin in palmar hyperhidrosis. Aesthet Surg J. 2013;33(2):295-297.

43. Benohanian A. Palmar hyperhidrosis. Needle-free anesthesia as an alternative to Bier's block and peripheral nerve blockade for botulinum toxin therapy. Dermatol Online J. 2006;12(6):26.

44. Benohanian A. Needle-free anesthesia: a promising technique for the treatment of palmoplantar hyperhidrosis with botulinum toxin A. Therapy. 2006;3(5):591-596.

45. Benohanian A. Surgical pearl: use of needle-free anesthesia in the treatment of palmar hyperhidrosis with botulinum A toxin. $\mathrm{J} \mathrm{Am} \mathrm{Acad}$ Dermatol. 2005;52(6):1073-1074. 
46. Patakfalvi L, Benohanian A. Needle-free anaesthesia, a promising option for the needle-phobic patient. Br J Dermatol. 2014;170(5):1191-1192.

47. Hamilton JG. Needle phobia: a neglected diagnosis. J Fam Pract. 1995;41(2):169-175.

48. Zackrisson T, Eriksson B, Hosseini N, Johnels B, Krogstad AL. Patients with hyperhidrosis have changed grip force, coefficient of friction and safety margin. Acta Neurol Scand. 2008;117(4):279-284.

49. Krogstad AL, Skymne BS, Goran Pegenius BS, Elam M, Wallin BG. Evaluation of objective methods to diagnose palmar hyperhidrosis and monitor effects of botulinum toxin treatment. Clin Neurophysiol. 2004;115(8):1909-1916.

50. Shome D, Nair AG, Kapoor R, Jain V. Botulinum toxin A: is it really that fragile a molecule? Dermatol Surg. 2010;36(Suppl 4):2106-2110.

51. Abell E, Munro DD. Intralesional treatment of alopecia areata with triamcinolone acetonide by jet injector. Br J Dermatol. 1973;88(1):55-59.

52. Sparrow G, Abell E. Granuloma annulare and necrobiosis lipoidica treated by jet injector. Br J Dermatol. 1975;93(1):85-89.

53. Saleem K, Azim W. Treatment of nail psoriasis with a modified regimen of steroid injections. J Coll Physicians Surg Pak. 2008;18(2):78-81.

54. Nantel-Battista M, Richer V, Marcil I, Benohanian A. Treatment of nail psoriasis with intralesional triamcinolone acetonide using a needlefree jet injector: a prospective trial. J Cutan Med Surg. 2014;18(1): 38-42.

55. Ledon JA, Savas J, Franca K, Chacon A, Nouri K. Intralesional treatment for keloids and hypertrophic scars: a review. Dermatol Surg. 2013;39(12):1745-1757.

56. Herschthal J, McLeod MP, Zaiac M. Management of ungual warts. Dermatol Ther. 2012;25(6):545-550.

57. Saray Y, Gulec AT. Treatment of keloids and hypertrophic scars with dermojet injections of bleomycin: a preliminary study. Int J Dermatol. 2005;44(9):777-784.
58. de Blois AW, Grouls RJ, Ackerman EW, Wijdeven WJ. Development of a stable solution of 5-aminolaevulinic acid for intracutaneous injection in photodynamic therapy. Lasers Med Sci. 2002;17(3):208-215.

59. Cappugi P, Mavilia L, Campolmi P, Reali EF, Mori M, Rossi R. New proposal for the treatment of nodular basal cell carcinoma with intralesional 5-aminolevulinic acid. J Chemother. 2004;16(5):491-493.

60. Sakamoto FH, Doukas AG, Farinelli WA, et al. Intracutaneous ALA photodynamic therapy: dose-dependent targeting of skin structures. Lasers Surg Med. 2011;43(7):621-631.

61. Baxter J, Mitragotri S. Jet-induced skin puncture and its impact on needle-free jet injections: experimental studies and a predictive model. J Control Release. 2005;106(3):361-373.

62. Prickett K, Ramsey M. Mohs Micrographic Surgery. Treasure Island, FL: StatPearls Publishing; 2017.

63. Rhodes LE, de Rie MA, Leifsdottir R, et al. Five-year follow-up of a randomized, prospective trial of topical methyl aminolevulinate photodynamic therapy vs surgery for nodular basal cell carcinoma. Arch Dermatol. 2007;143(9):1131-1136.

64. Barolet D. No-needle jet intradermal ALA-PDT for recurrent nodular BCC: a treatment alternative to Mohs micrographic surgery? Lasers Surg Med. 2015;47(S26):38.

65. Behroozan DS, Goldberg LH. Dermal tumescent local anesthesia in cutaneous surgery. J Am Acad Dermatol. 2005;53(5):828-830.

66. Pearson ICaCS. Botulinum toxin type A treatment for axillary hyperhidrosis: A comparison of intradermal and subcutaneous injection techniques. Br J Dermatol. 2004;151(s68):96.

67. Shelley WB, Talanin NY, Shelley ED. Botulinum toxin therapy for palmar hyperhidrosis. J Am Acad Dermatol. 1998;38(2 pt 1):227-229.

68. Heckmann M, Schalier M, Plewig G, Ceballos-Baumann A. Optimizing botulinum toxin therapy for hyperhidrosis. $\mathrm{Br} J$ Dermatol. 1998;138(3):553-554.
Clinical, Cosmetic and Investigational Dermatology

\section{Publish your work in this journal}

Clinical, Cosmetic and Investigational Dermatology is an international, peer-reviewed, open access, online journal that focuses on the latest clinical and experimental research in all aspects of skin disease and cosmetic interventions. This journal is included on PubMed. The manuscript management system is completely online

\section{Dovepress}

and includes a very quick and fair peer-review system, which is all easy to use. Visit http://www.dovepress.com/testimonials.php to read real quotes from published authors 